\title{
Early Intervention on Autism: What Do We Need to Know?
}

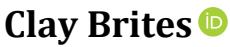 \\ Neurosaber Institute, Londrina, Parana, Brazil \\ Email: claybrites@gmail.com
}

How to cite this paper: Brites, C. (2020). Early Intervention on Autism: What Do We Need to Know? Psychology, 11, 1081-1090. https://doi.org/10.4236/psych.2020.118071

Received: July 1, 2020

Accepted: August 4, 2020

Published: August 7, 2020

Copyright $\odot 2020$ by author(s) and Scientific Research Publishing Inc. This work is licensed under the Creative Commons Attribution International License (CC BY 4.0).

http://creativecommons.org/licenses/by/4.0/

\section{(c) (i) Open Access}

\begin{abstract}
The early intervention on Autism Spectrum Disorders (ASD) is the best treatment and most efficient to improve core signs of this neurodevepmental disorder. Specially, before two years-old, specifics methods and approachments can move your prognostic and preserve cognitive aspects, QI size, language and emotional self-regulation. What step-by-step is necessary to suspect and confirm ASD diagnosis? This paper resumes and describes succinctly the diagnostical assessment and therapeutics around early intervention on autism.
\end{abstract}

\section{Keywords}

Autism, Early Intervention, ASD, Autism Spectrum Disorders, Diagnosis

\section{Introduction: The Importance of Early Diagnosis and Intervention on Autism}

Autistic Spectrum Disorder (ASD) is a condition characterized by deficits in social interaction, abnormalities in social communication, repetitive behaviors and interests that are excessively restricted and at odds with the social context [American Psychiatric Association, 2013]. It affects 1\% to 1.5\% of children and leads to consequent problems such as, social, adaptive and linguistic development (Van Rooij et al., 2018; Bosa et al., 2016). Its clinical condition can start early at birth, in $70 \%$ of cases, and in late cases, at the start of age three, in 30\% of the cases described (Schreibman et al., 2015). It can transpire with sensory problems, social phobia, difficulties in recognizing facial expressions of emotion, eating and sleep abnormalities further destabilizing its functioning in social relations and structured activities (Brites \& Brites, 2018).

From early childhood to late one, ASD leads to great limitations in the acqui- 
sition of neurodevelopment, a decrease in intellectual potential, linguistic weaknesses and severe delays in social life and school learning. The effects of ASD are prolonged throughout the cycle of life, negatively impacting the most diverse contexts and stages of development of children and adolescents, and in the final stages of adolescence and adulthood, may bring together a collection of abnormalities with different consequences on affective life, emotional, academic and various subjective breakdowns (Vannucci et al., 2014). If no early approach, therapeutics are taken, punctual or global delays and regressions will persist. What's more, if nothing is done before the age of 3 , little or no significant change to plan or remedy severe behaviors will happen in the future (Lord \& Bishop, 2015).

Surrounded by several recurrent researches about the best possible therapeutic strategies, ASD has no cure. There are no pharmacological or non pharmacological treatments that fully resolve symptoms and behavioral abnormalities and scientifics evidences demonstrate that only early interventions, before 3 years of age, are considered effective for qualitatively and quantitatively modifying their evolution and functional impairments and these are possible through retrospective videos, media analysis, relatives and teachers reports (Zwaigenbaum et al., 2015). They prevent cognitive-intellectual deterioration, improve language skills and help preserve the child's adaptive potential as much as possible (Bradshaw et al., 2014). However, only when the diagnosis is confirmed before 3 years-old and, in some cases, until the 4 years-old, it is possible to glimpse these effects with optimism.

Myths and inconsistencies in the knowledge of this neurodevelopmental disorder still prevail in most health and education professionals. In several countries, between the suspicion and the diagnostic confirmation of Autism, it takes between 36 and 40 months. The causes are diverse and involve incredulity, lack of knowledge, fear of facing the diagnosis, problems in primary care, lack of specialists, and in the context of family, overestimation of the positive points of some children with ASD and relatives that discourage parents to seek a specialized evaluation (Ribeiro et al., 2017). As the symptoms, the intensity and clinical picture of ASD are extremely varied and can be masked by its various comorbidities (such as Attention Deficit Hyperactivity Disorder (ADHD), Oppositional Defiant Disorder (ODD) and Mood Disorders), high abilities/giftedness and sensory difficulties and, several times, the suspicions are postponed and the possibilities of their existence are discredited (Rutherford et al., 2018; Durkin et al., 2015). For example, children with intense hyperactivity can delay the diagnosis of ASD by up to six years (Matson et al., 2013). Its diagnosis is essentially clinical, depends on reports from caregivers, schools and use of specific scales and there are no biological markers, which can complicate the trajectory of confirmation (Silva \& Mulick, 2009).

In the face of such challenges, in-depth knowledge about Autism is the most valuable weapon against late diagnosis. First published in the 1940s, it was best described at the start of the 1970s, but only better understood and systematized 
for a better diagnostic approach in the last 20 years; since then, more evidence with high validity and scientific reliability for its therapeutic conduct has been gathered only in the last 10 years. Therefore, there is still little time to disseminate as much information as necessary for professionals and people who need it most: Those who serve on the front line of primary health care in the most diverse municipalities.

\section{How to Identify as Early as Possible: Early Diagnosis}

Early diagnosis must permeate the practice of all health and education agents who care for children in all related institutions (day care centers, clinical offices, non-physicians, primary schools, emergency rooms, family health and pediatricians). These professionals must be trained and updated on observation of child behavior, milestones of psychomotor development, early signs of autism, risky behaviors and structured scales of screening (Seize \& Borsa, 2017).

In autism, early diagnosis is a process that seeks to confirm, from clinical suspicion to condition of spectrum in a child before three years of age. Some authors and researchers, however, argue that it should be done under the age of two (Constantino \& Charman, 2015). It involves extensive knowledge about the normal parameters of child development and behavior, the behavioral signs of risk, clinical observation and the use of screening scales (Table 1).

Basic knowledge about the stages of child neurodevelopment is essential for everyone who is dedicated to working with children, whether they are health, education professionals, social workers, educators, teachers, caregivers, nannies, etc. It allows us to be attentive to each stage, especially up to 3 years of age. The World Health Organization (WHO) has, since the beginning of this decade, promoted and published the need to identify neurodevelopmental disorders (ADHD, Intellectual Disabilities, Language and Communication Disorders, Motor Disorders, learning disorders and autism spectrum disorder) (Noer \& Halpern, 2018). These conditions, highly inheritable, with a large share of genetic etiology, are considered as one of the main factors of morbidity and limitations of human life leading to significant impacts on mental and physical health, academic adversities and significant professional career and relationship problems. There is evidence that it can lead to future greater risks of metabolic diseases, obesity, hypertension and diabetes in adulthood (Rohde et al., 2019).

Table 1. Essential components for early diagnosis of autism.

\begin{tabular}{cl}
\hline Parameters & \multicolumn{1}{c}{ Description } \\
\hline $\begin{array}{c}\text { Normal stages of } \\
\text { development/Behavior }\end{array}$ & $\begin{array}{l}\text { Scale of motor development, linguistic, adaptive, } \\
\text { cognitive and social from the ages of 0 to 5 years of age; } \\
\text { Ages and Stages Questionnaire (ASQ-3) }\end{array}$ \\
Signs of risk & Signs of risk until 2 years of age ("Redflags") \\
Sorting scales & Scale of autistic traits, M-CHAT and \\
& Autism Screening Questionnaire $(A S Q)$ \\
\hline
\end{tabular}


In regard to dentists, the risk is higher for periodontal problems, cavities, food and poor oral hygiene habits and patients tend to suffer because they often forget how guidelines and health care are often carriers of the same pathologies. The early diagnosis in these cases (even if late) may help to improve their management in the dental office and allow greater for control and support of therapeutic measures. The autism spectrum disorder fits perfectly in this context. As mentioned above, early diagnosis can reduce the symptoms of autism spectrum disorder and promote a much more "round" and favorable evolution for this child. But as soon as we are able to suspect ASD, first, we will be able to identify developmental delays or deviations in children.

The assessment of milestones of child development must be systematically observed in 5 main axes: motor, linguistic, social, cognitive and adaptive. The motor assesses the evolution of achievements in stages according to the chronological age of posture, balance, skills to sit, crawl, walking without support and with support, etc. The language assesses the acquisition of physical, non-verbal and verbal reactions to communication with peers. The social evaluates the perception of the other, shared attention, social reciprocity and social communication skills. The cognitive evaluates the sequential steps of how the child can explore the space in which he lives. The adaptive, in turn, assesses the stages of how the child manages to conquer and master routines, rules and tools used by his culture and family. These axes represent the evolutionary acquisitions necessary to build new skills that will underpin the plasticity of new brain connections and structures that will allow new learning and so on. The phase of greatest neuroplasticity occurs in the first 3 years of age but it still spreads with significant permeability to change until 5-6 years of age. For this reason, the importance of identifying development problems as early as possible: it allows that still in the "construction" phase, we can really remedy or reduce disturbances.

Access to knowledge about these steps is concentrated on the neurodevelopment scales (Table 2). They help memorize and systematize observation in the work of professionals who evaluate children and can be accessed on the internet, in books, periodicals and in vaccination cards. Usually used by pediatricians, neurologists and child psychiatrists, they can also be regularly accessed by any professional or area. (It is never too much to remember that neurodevelopmental disorders, including ASD, are often associated with genetic syndromes and these, in turn, have a high prevalence in anomalies of interest for all.)

The risk signs for suspecting Autism in a child under 2 years of age are called "red flags" (Table 3). This denomination fits perfectly in its objectives: to alert the evaluator of the presence or absence of signs of Autism during contact with the child, regularly leading to an active screening (Naguy, 2018).

The American Academy of Pediatrics recommends that on 18 and 24-months of age, pediatricians should have these signs in their mental routine or by means of scales so that they are included, during the consultation, in childcare, to verify it's presence (Van Rooij et al., 2018; Zwaigenbaum et al., 2015). The presence of 
Table 2. Neurodevelopment scales applicable in the first years of life to milestones assessment.

\begin{tabular}{|c|c|}
\hline Scales of neurodevelopment & Specificities \\
\hline Denver scale-II & $\begin{array}{l}\text { Directly with the child; } \\
\text { rate from the age of } 0 \text { to } 6 \text { years of age. }\end{array}$ \\
\hline Ages and Stages Questionnaire (ASQ) & $\begin{array}{l}\text { Questionnaire and direct observation; } \\
4 \text { to } 6 \text { years of age. }\end{array}$ \\
\hline $\begin{array}{c}\text { Parents' Evaluation of } \\
\text { Developmental Status (PEDS) }\end{array}$ & $\begin{array}{l}\text { Questionnaire with the parents or caregiver. } \\
0 \text { to } 8 \text { years of age. }\end{array}$ \\
\hline Pediatric Symptom Checklist (PSC) & Psychosocial questionaire; from the ages of 4 to 18 . \\
\hline
\end{tabular}

Table 3. The "red flags" signs suggested of autism.

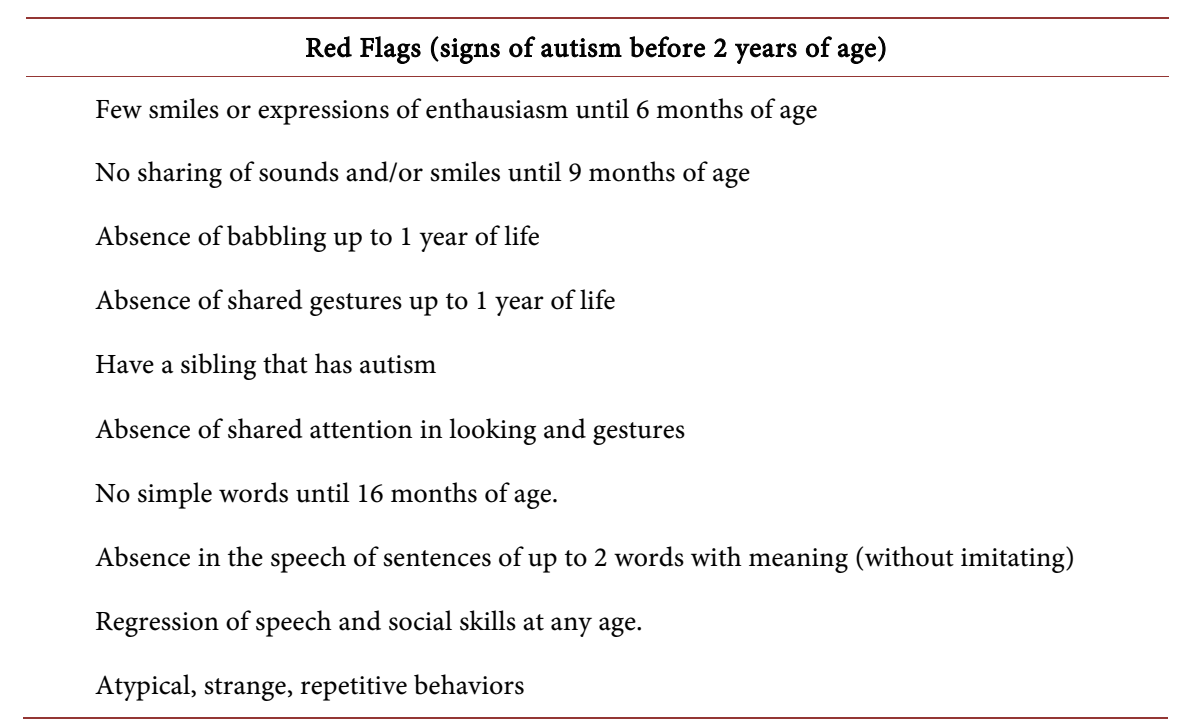

any of these signs authorizes the professional to refer the child to a specialized evaluation.

The ASD cognitive features affect child development because it leads to delays or deviations in social attention skills (abnormal social engagement and lack of interaction initiative), shared attention, social reciprocity and non-verbal and verbal communication/language inability. These limitations progressively produce more limitations that, if not remedied or reduced in time, will inhibit new more complex skills. These delays are expressed in behavior and social conduct and can be observed when in contact with the child in various environments.

The use of autism screening scales (ASD) is a very practical, quick and relatively effective way to screen people or children who may be acting with ASD in the common population. These scales do not close or conclude whether the child has Autism or not. They serve to screen and, if positive, signal high risk and child must be specialists. They are easy to apply, accessible to lay people and professionals, quick and are useful to compose interviews directed to their caregivers, members of schools and children's centers (Volkmar et al., 2014) (Table 4). 
Table 4. Commom and avaliable screening scales to autism.

\begin{tabular}{cl}
\hline Screening scales & \multicolumn{1}{c}{ Peculiarities } \\
\hline ATA & $\begin{array}{c}15 \text { items composed of specific sub-items with greater } \\
\text { descriptions and can be applied up to } 5 \text { years of age. }\end{array}$ \\
M-CHAT & 23 items of atypical and critical signs; tracks children \\
(Modified-Checklist Autism in Toddlers) & with ages from 18 to 30 months. \\
& 40 items; useful to track autismo from 3 to 6 years \\
ASQ & $\begin{array}{c}\text { old and helps in the diferentiation between ASD } \\
\text { and Language Disorders; assesses children }\end{array}$ \\
(Autism Screening Questionnaire) & who do not yet speak. \\
Behavioral Assessment Protocol & $\begin{array}{l}\text { It is evalutated based on the three axes of social } \\
\text { skills related to autismo: Shared attention, }\end{array}$ \\
for children with Suspected Autism & symbolic play and repetitive behaviors; \\
Spectrum Disorder-Revised & created and developed in Brazil.
\end{tabular}

\section{Types and Effects of Early Interventions}

From the first experiences and, soon after, the first evidence of therapies that could be useful for the management of ASD, several groups of researchers started to dedicate themselves to the development of early intervention models. The appearance of these models started from the first positive descriptions through Applied Behavior Analysis in the early 1980s. This model, of a psychological behavioral line based on Skinner's behaviorist theories, revealed that through positive reinforcement mechanisms, contingency and strategies that induce self-regulation and generalization of behaviors through systematic changes in the environment, many children appeared to reduce inflexible behaviors and started to advance in order to improve social interaction and communication [BACB, 2014].

Over time, it was found that some children, especially those under the age of four, needed behavioral therapies more appropriate to their age and that were more directed towards the remediation of perceptual, sensory, social attention and social skills, and strategies that prioritize developmental or function delays, that the child might not have acquired, because of the gradual or regressive establishment of Autism. Thus, the Denver Early Intervention Model (ESDM) emerged in the early 1990s (Rogers \& Talbott, 2016).

Currently, these two types of intervention are considered the most effective means to early reduce the negative impact of ASD on the child's development and behavior (Lai et al., 2014). Both have essential characteristics for this purpose: they are intensive, can be applicable in natural environments for children (home and school) and parents, caregivers, teachers can be trained and co-opted to serve, at all times, as "therapists" for their own children with autism, or formally known as parent-mediated interventions. These types of interventions have been named Naturalistical Behavioral Developmental Interventions (NBDI). They are strategies that have as its main focus the development and behavioral actions of naturalistic application that are mediated by parents (Schreibman et al., 2015). In addition to the models mentioned above, there are others (Table 5). 
Table 5. Structured models of early interventions for children with ASD in the first years of life.

\begin{tabular}{cc}
\hline Early interventions (NBDI) & $\begin{array}{c}\text { Early therapies mediated } \\
\text { by parents or caregivers }\end{array}$ \\
RIT & $\begin{array}{c}\text { DIR-Floor time } \\
\text { (Reciprocal Imitation Training) } \\
\text { ESDM }\end{array}$ \\
$\begin{array}{c}\text { (Developmental Individual-Difference } \\
\text { Relationship-Based Model) }\end{array}$ \\
ESI \\
PRT & (Early Social Interaction) \\
(Pivotal Response Treatment) & ESDM \\
SCERTS & (Early Start Denver Model) \\
(Social Communication/Emotional & PACT \\
Regulation/ Transactional Support) & JASPER \\
JASPER & (Preschool Autism Communication Trial) \\
(Joint Attention Symbolic Play & Engagement and Regulation) \\
Engagement and Regulation) & \\
Project impact &
\end{tabular}

The effect of these interventions has been well described in literature and are among the most cited and documented for the preservation of intellectual potential, improvement of language parameters and improvement of adaptive IQ (Elders et al., 2017). They help stop the advance of stereotypes and improve social engagements and reciprocity. By including the family in the process, it increases the self-esteem of the caregiver and they start to positively glimpse their child's destiny and involve them in the results leading to co-responsibility and commitment that reduce the risks of giving up or discontinuing treatment (Gardiner \& Iarocci, 2015; Rogers et al., 2019).

\section{Conclusion}

Evidences have established importance of early diagnosis and intervention on ASD as its severe negative impact throughout life. Therefore, interdisciplinary and transdisciplinary knowledge about child neurodevelopmental typical milestones is essential and fundamental requirement to identify delays or atypical behaviours. In this way, ASD teaching on university graduates, post-graduates and constant uploading should be included in the courses schedules to all areas. The absence of ASD specialists on primary attention healthy and educational services is worrisome and permanent. Everyone should know suggestive signs of autism. Fortunately, with the advancement of the internet and networking, this knowledge has been available for all more easily.

The diversified teaching of intervention models in autism based on NDBI should be encouraged. Health and education professionals must learn to implement them in their clinical practice because the therapeutic management of autism requires rehabilitation strategies that involve the promotion of sensory per- 
ception, social cognition and non-verbal communication traditionally rarely addressed in graduation.

\section{Conflicts of Interest}

The author declares no conflicts of interest regarding the publication of this paper.

\section{References}

American Psychiatric Association (2013). Diagnostic and Statistical Manual of Mental Disorders DSM-5 (5th ed.) Washington DC: American Psychiatric Association. https://doi.org/10.1176/appi.books.9780890425596

BACB (2014). Applied Behaviour Analysis Treatment of Autism Spectrum Disorder: Practice Guidelines for Healthcare Funders and Managers (2nd ed.). Behaviour Analyst Certification Board.

Bosa, C. A., Zanon, R. B., \& Backes, B. (2016). Autismo: Construção de um Protocolo de Avaliação do Comportamento da Criança-Protea-R. Psicologia: Teoria e Prática, 18, 194-205. https://doi.org/10.15348/1980-6906/psicologia.v18n1p194-205

Bradshaw, J., Steiner, A. M., Gengoux, G., \& Koegel, L. K. (2014). Feasibility and Effectiveness of Very Early Intervention for Infants At-Risk for Autism Spectrum Disorder: A Systematic Review. Journal of Autism and Developmental Disorders, 45, 778-794. https://doi.org/10.1007/s10803-014-2235-2

Brites, L. M. D., \& Brites, C. (2018). Mentes Únicas. São Paulo: Gente.

Constantino, J. N., \& Charman, T. (2015). Diagnosis of Autism Spectrum Disorder: Reconciling the Syndrome, Its Diverse Origins, and Variation in Expression. The Lancet Neurology, 15, 279-291. https://doi.org/10.1016/S1474-4422(15)00151-9

Durkin, M. S., Elsabbagh, M., Barbaro, J., Gladstone, M., Happe, F., Hoekstra, R. A., Lee, L., Rattazzi, A., Stapel-Wax, J., Stone, W. L., Tager-Flusberg, H., Thurm, A., Tomlinson, M., \& Shih, A. (2015). Autism Screening and Diagnosis in Low Resource Settings: Challenges and Opportunities to Enhance Research and Services Worldwide. Autism Research, 8, 473-476. https://doi.org/10.1002/aur.1575

Elders, J. H., Kreider, C. M., Brasher, S. N., \& Ansell, M. (2017). Clinical Impact of Early Diagnosis of Autism on the Prognosis and Parent-Child Relationships. Psychology Research Behavioural Management, 10, 283-292. https://doi.org/10.2147/PRBM.S117499

Gardiner, E., \& Iarocci, G. (2015). Family Quality of Life and ASD: The Role of Child Adaptive Functioning and Behavior Problems. Autism Research, 8, 199-215. https://doi.org/10.1002/aur.1442

Lai, M. C., Lombardo, M. V., \& Baron-Cohen, S. (2014). Autism. The Lancet, 383, 896-910. https://doi.org/10.1016/S0140-6736(13)61539-1

Lord, C., \& Bishop, S. L. (2015). Recent Advances in Autism Research as Reflected in DSM-5 Criteria for Autism Spectrum Disorder. Annual Review Clinical Psychology, 11, 53-70. https://doi.org/10.1146/annurev-clinpsy-032814-112745

Matson, J. L., Rieske, R. D., \& Williams, L. W. (2013). The Relationship between Autism Spectrum Disorders and Attention-Deficit/Hyperactivity Disorder: An Overview. Research in Developmental Disabilities, 34, 2475-2484.

https://doi.org/10.1016/j.ridd.2013.05.021

Naguy, A. (2018). A Roadmap to Clinical Assessment and Evaluation of Autism Spectrum Disorder. Journal of Family Medicine and Primary Care, 6, 883-884. 
https://doi.org/10.4103/jfmpc.jfmpc $426 \quad 16$

Noer, C., \& Halpern, R. (2018). O pediatra e a promoção do desenvolvimento infantil: Otimizando a consulta. Residência Médica, 8, 156-162. https://doi.org/10.25060/residpediatr-2018.v8n3-12

Ribeiro, S. H., Paula, C. S., Bordini, D., Mari, J. J., \& Caetano, S. C. (2017). Barriers to Early Identification of Autism in Brazil. Revista Brasileira de Psiquiatria, 39, 352-354. https://doi.org/10.1590/1516-4446-2016-2141

Rogers, S. J., \& Talbott, M. R. (2016). Early Identification and Early Treatment of Autism Spectrum Disorder. In International Review of Research in Developmental Disabilities (Vol. 50, pp. 233-275). Amsterdam: Elsevier. https://doi.org/10.1016/bs.irrdd.2016.05.004

Rogers, S. J., Estes, A., Vismara, L., Munson, J., Zierhut, C., Greenson, J., Dawson, G., Rocha, M., Sugar, C., Senturk, D., Whelan, F., \& Talbott, M. (2019). Enhancing Low-Intensity Coaching in Parent Implemented Early Start Denver Model Intervention for Early Autism: A Randomized Comparison Treatment Trial. Journal of Autism Development Disorder, 49, 623-646. https://doi.org/10.1007/s10803-018-3740-5

Rohde, L. A., Buitelaar, J. K., Gerlach, M., \& Faraone, S. V. (2019). The World Federation of ADHD Guide. Porto Alegre: Artmed.

Rutherford, M., Burns, M., Gray, D., Bremner, L., Clegg, S., Russell, L., Smith, C., \& O'Hare, A. (2018). Improving Efficiency and Quality of the Children's ASD Diagnostic Pathway: Lessons Learned from Practice. Journal of Autism Development Disorder, 48, 1579-1595. https://doi.org/10.1007/s10803-017-3415-7

Schreibman, L., Dawson, G., Stahmer, A. C., Landa, R., Rogers, S. J., McGee, G. G., Kasari, C., Ingersoll, B., Kaiser, A. P., Bruinsma, Y., McNerney, E., Wetherby, A., \& Halladay, A. (2015). Naturalistic Developmental Behavioral Interventions: Empirically Validated Treatments for Autism Spectrum Disorder. Journal of Autism Development Disorder, 45, 2411-2428. https://doi.org/10.1007/s10803-015-2407-8

Seize, M. M., \& Borsa, J. C. (2017). Instrumentos para rastreamento de sinais precoces do autismo: Revisão sistemática. Psico-USF, 22, 161-176. https://doi.org/10.1590/1413-82712017220114

Silva, M., \& Mulick, J. A. (2019). Diagnosticando o transtorno autista: Aspectos fundamentais e considerações práticas. Psicologia: Ciência e Profissão, 29, 116-131. https://doi.org/10.1590/S1414-98932009000100010

Van Rooij, D., Anagnostou, E., Arango, C., Auzias, G., Behrmann, M., Busatto, G. F. et al. (2018). Cortical and Subcortical Brain Morphometry Differences between Patients with Autism Spectrum Disorder and Healthy Individuals across the Lifespan: Results from the ENIGMA ASD Working Group. American Journal of Psychiatry, 175, 359-369.

https://doi.org/10.1176/appi.ajp.2017.17010100

Vannucci, G., Masi, G., Toni, C., Dell’Osso, L., Marazziti, D., \& Perugi, G. (2014). Clinical Features, Developmental Course and Psychiatric Comorbitidy of Adult Autism Spectrum Disorder. CNS Spectrums, 19, 157-164.

https://doi.org/10.1017/S1092852913000941

Volkmar, F., Siegel, M., Woodbury-Smith, M., King, B., McCracken, J., State, M., \& The American Academy of Child and Adolescent Psychiatry (AACAP) Committee on Quality Issues (CQI) (2014). Practice Parameter for the Assessment and Treatment of Children and Adolescents with Autism Spectrum Disorder. Journal of American Academy Children and Adolescence Psychiatry, 53, 237-257.

https://doi.org/10.1016/j.jaac.2013.10.013

Zwaigenbaum, L., Bauman, M. L., Stone, W. L., Yirmiya, N., Estes, A., Hansen, R. L., 
McPartland, J. C., Natowicz, M. R., Choueiri, R., Fein, D., Kasari, C., Pierce, K., Buie, T., Carter, A., Davis, P. A., Granpeesheh, D., Mailloux, Z., Newschaffer, C., Robins, D., Roley, S. S., Wagner, S., \& Wetherby, A. (2015). Early Identification of Autism Spectrum Disorder: Recommendations for Practice and Research. Pediatrics, 136, S10-S40. https://doi.org/10.1542/peds.2014-3667C 